\section{Who will pay for treatments administered in outpatient units?}

\author{
Des Leddin MB FRCPC \\ President Elect, the Canadian Association of Gastroenterology
}

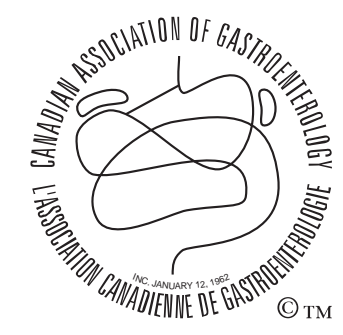

En français voir page 402
A lmost one-third of Canadian patients who have Crohn's disease or ulcerative colitis are without drug plan insurance. However, even those who have a drug plan can find themselves in for a surprise if they present a prescription to a pharmacist for antitumour necrosis alpha antibodies. Patients have found that neither their insurance company nor the hospital where they receive the agent will cover the cost of the drug.

The problem arises because these newer therapeutics have to be given by intravenous infusion in a setting where allergic reactions can be treated. In the Canadian system, this generally means an outpatient day treatment unit. Hospital's can argue that these patients are outpatients and that the drug expense is, therefore, not the hospital's problem. Insurance companies point to the Canada Health Act and say that the hospital is responsible. The patient and the gastroenterologist can find themselves unable to get anyone to take final responsibility.

Where does the truth lie? The Canada Health Act of 1984 (http://laws.justice.gc.ca/en/C-6/16506.html) defines a hospital as "any facility or portion thereof that provides hospital care, including acute, rehabilitative or chronic care". Hospital services are defined by the act as "services provided to in-patients or out-patients at a hospital, if the services are medically necessary for the purpose of maintaining health, preventing disease or diagnosing or treating an injury, illness or disability". Furthermore, the act specifically states that "drugs, biologicals and related preparations when administered in the hospital" are included as hospital services. The act also states that "In order to satisfy the criterion respecting comprehensiveness, the health care insurance plan of a province must insure all insured health services provided by hospitals." Accordingly it appears that, under the terms of the Canada Health Act, hospitals are indeed obliged to cover the cost of drugs administered in day units.

The private sector could also argue that it has already taken on considerable costs and should not be asked to contribute more. According to the Canadian Institute for Health Information (http://www.cihi.ca/), Canadian hospitals had 25\% fewer beds in 1997/98 than in 1984/85. Rates of day surgery have more than doubled over the same period. Much of the cost of this change has been borne by individuals and by insurance companies.

In defense of the hospital's position, it should be pointed out that they are dependent on provincial governments for funding and, apart from the occasional coffee franchise, have few options when it comes to raising revenue. Although it is difficult under the Canada Health and Social Transfer arrangement to track dollars through the system, it is clear that hospital budgets continue to face severe constraints. In contrast to hospitals, the insurance companies can increase revenue by raising premiums, albeit at a cost to policyholders, stockholders and their competitive position.

The Canadian Association of Gastroenterology (CAG) has sought input on this issue from the Provincial Gastroenterology Associations, the Practice Affairs Committee and members of the governing board. The position of the CAG is that all constituencies must work to provide patients with the treatment they need, with the least obstacles, in the most fiscally responsible way. The CAG will contact provincial and federal government representatives to highlight this issue. We will encourage representatives of insurance companies, provincial, and federal government to meet and to develop new rules governing outpatient treatment of patients with gastrointestinal disorders. There is a new reality concerning outpatient treatment. For our patients' sake, it is time to recognize the new manner in which the practice of medicine will be delivered in the future.

The CAG is proud to acknowledge its Benefactor Corporate Sponsors:
Abbott Laboratories Ltd.
AstraZeneca Canada Inc.
Axcan Pharma Inc. 


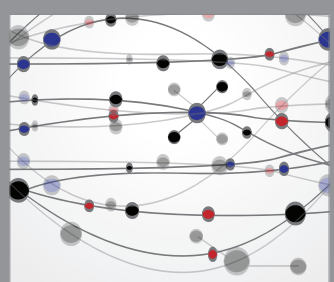

The Scientific World Journal
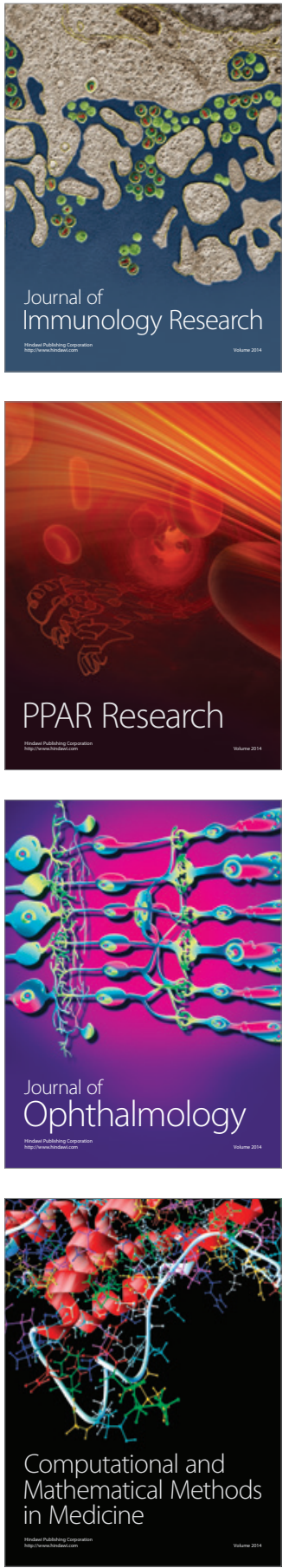

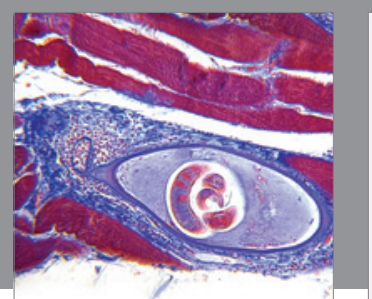

Gastroenterology Research and Practice

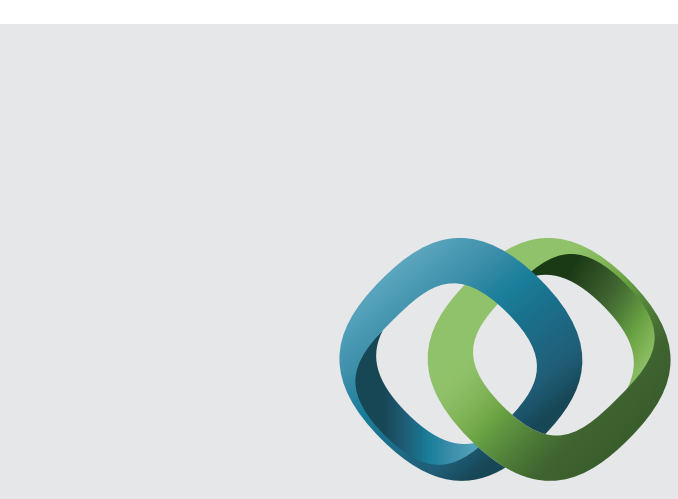

\section{Hindawi}

Submit your manuscripts at

http://www.hindawi.com
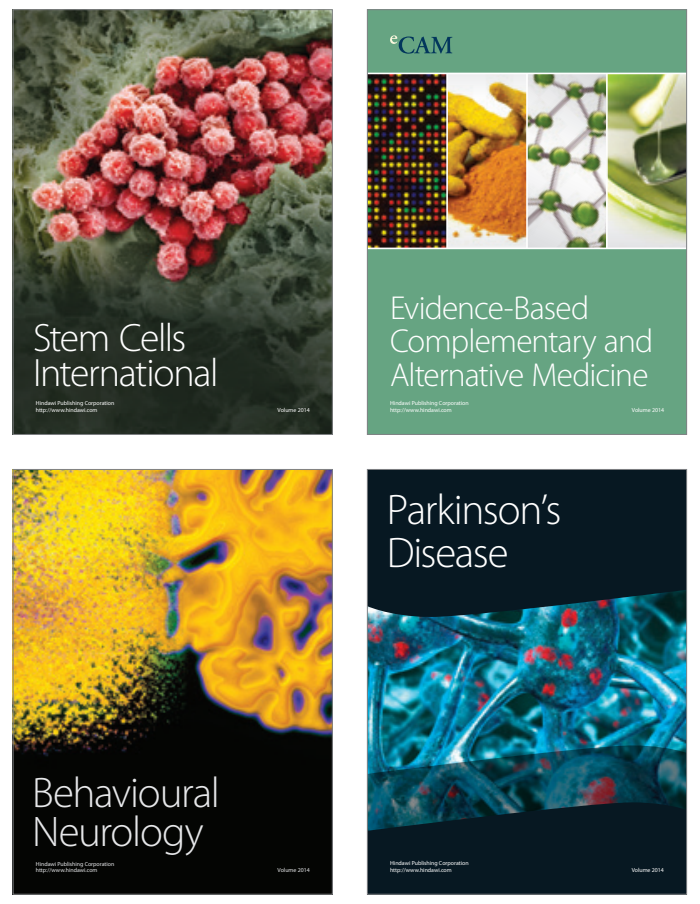
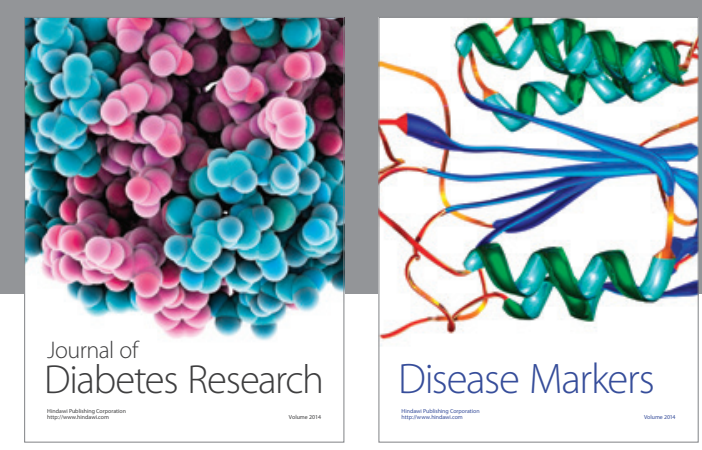

Disease Markers
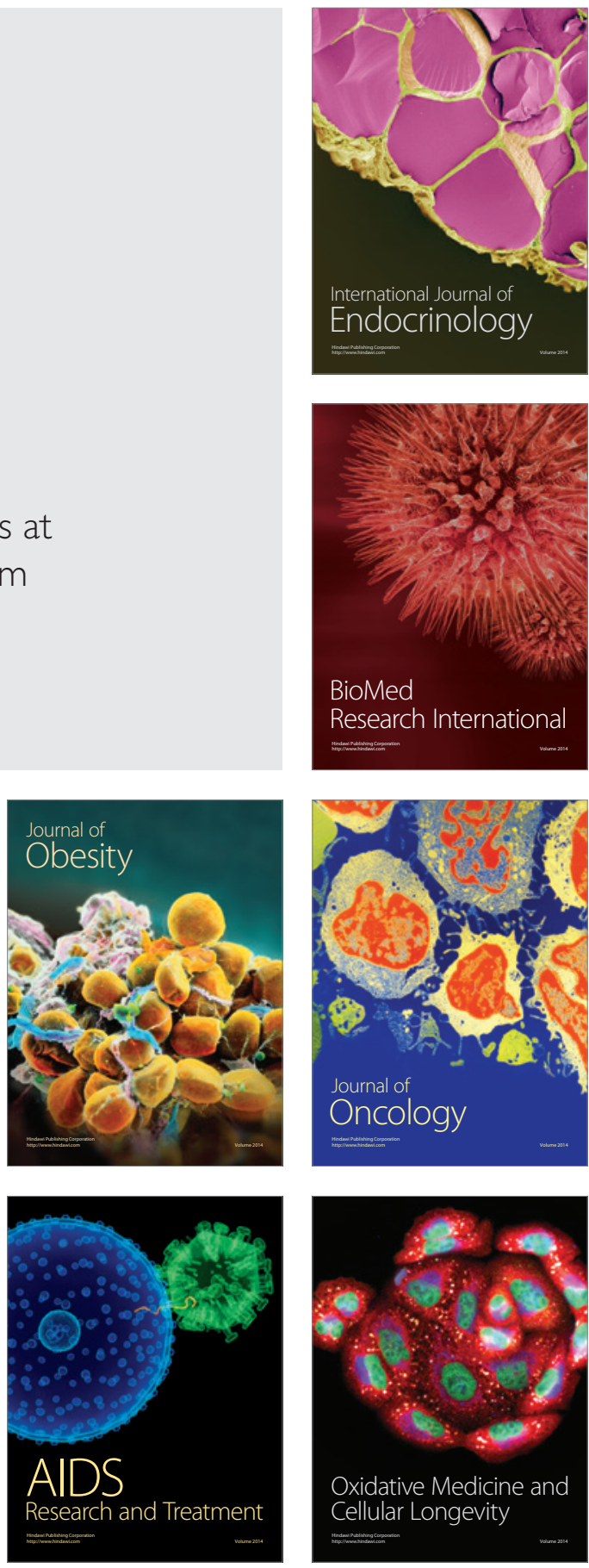